Research Article

\title{
An Experimental Investigation of the Progressive Failure of Sandstone and Its Energy Evolution Characteristics
}

\author{
Yan Chen $\mathbb{D}^{1}$ and Baohua Guo iD $^{1,2}$ \\ ${ }^{1}$ School of Energy Science and Engineering, Henan Polytechnic University, Jiaozuo, Henan 454003, China \\ ${ }^{2}$ Collaborative Innovation Center of Coal Work Safety, Jiaozuo, Henan 454003, China \\ Correspondence should be addressed to Baohua Guo; guobaohua@139.com
}

Received 3 July 2018; Accepted 10 September 2018; Published 14 October 2018

Guest Editor: Guo-zhong Hu

Copyright ( ) 2018 Yan Chen and Baohua Guo. This is an open access article distributed under the Creative Commons Attribution License, which permits unrestricted use, distribution, and reproduction in any medium, provided the original work is properly cited.

\begin{abstract}
In this research study, the progressive failure and energy evolution characteristics of sandstone samples with different sizes were explored under uniaxial and triaxial compression conditions. The characteristic stresses and strains were captured using the crack axial strain levels and dissipative energy. The results showed that, with the increase in the ratios of the height to diameter $(H / D)$, the crack closure stresses increased, while the crack damage stresses decreased. However, the levels of both the crack closure stresses and crack damages were observed to increase with the $H / D$. With increase in the confining pressure, it was found that the crack closure and crack damage stresses increased, while their levels decreased. The strains of the crack closures, peak crack axial, and crack propagation were observed to decrease with the $H / D$, while the crack closure strain levels increased. Also, the crack propagation strains were observed to increase with the confining pressures, while the crack closure, peak crack axial, and crack closure strain levels decreased. The progress failure of the sandstone samples was also obtained based on the evolution characteristics of the dissipative energy. The relationship between the energy densities during each phase and the $H / D$ was also analyzed. It was determined that, with the increasing of the $H / D$, the input, elastic, and dissipative energy densities displayed different evolution characteristics. Furthermore, with the increases in the characteristic stresses, the input and elastic energy densities were found to increase. The dissipative energy density displayed a slight increase with the increases in the peak strength, which resulted in variations with regard to the crack closures and crack damage stresses.
\end{abstract}

\section{Introduction}

In underground coal and metal mining, the stabilities of the coal and ore pillars have become important influences on the safety of workers. It is known that rock pillars with different sizes have different mechanical properties, which are often referred to as the size effects or scale effects. A clear understanding of the progressive failure in rocks with different sizes is a significant key to the assessments of rock bursts or coal bumping in underground mining processes. Meanwhile, it is known that the dissipation and release of energy play crucial roles in rock failures. Therefore, it has become necessary to investigate the progressive failures and energy evolution characteristics of different sized rock and rock masses.
In previous studies, laboratory tests have been the most effective methods by which the progressive failure of rocks is examined. For example, Bieniawski [1] investigated the mechanism of brittle rock fractures using theoretical analysis and experimental methods. The results indicated that the progressive failure of rocks including crack closure, linear elastic deformations, fracture initiations, stable fracture propagation, and unstable fracture propagation before peak strength was achieved. Since the aforementioned study was conducted, methods to recognize the progressive failure of brittle rock have become fundamental topics of great interests to many researchers and engineers in the rock mechanics and engineering fields. It has been found by plotting the axial, lateral, and calculated volumetric strains versus the axial stresses that the paths of rock 
sample failures, along with the characteristic stresses, including crack closure, crack initiation, and crack damage stresses, can be identified [2]. Acoustic emission (AE) techniques have been used to identify the different stages of crack development. It has been determined that acoustic events are markedly different due to the loading before and after the initiations of cracks in rock [3]. Also, by using the axial stiffness, lateral stiffness, volumetric stiffness, and crack volume stiffness, the crack initiation and propagation thresholds in brittle rocks can be identified [4]. Cai et al. [5] proposed generalized crack initiation and crack damage thresholds of rock masses. Xue et al. [6] investigated the crack damage stress thresholds of different types of rock based on uniaxial compression. The results showed that the ratio of crack damage stress to uniaxial compressive strength (UCS) could potentially be an essential intrinsic property for low-porosity rock.

It has become well known from the previous laboratory tests that the mechanical behaviors of rock are dependent on the sizes and shapes of the specimens during uniaxial or triaxial compressions. These findings have been discussed in previous studies, and some empirical size-effect models were proposed [7-13]. However, the crack evolution characteristics of rock with different sizes have not yet been investigated in detail. Furthermore, the progressive failure of rock is known to be closely related to energy dissipation, due to crack evolution under compression. Huang and Li [14] presented the results of a series of triaxial compression tests on marble. The results indicated that there was a relationship between the strain energy conversion and the unloading rates, which were discussed in detail in the aforementioned study. Peng et al. [15] conducted triaxial compression tests in order to investigate the relationship between the energy transformation and coal failures. Also, by conducting uniaxial loading and unloading compression tests, Meng et al. [16] were able to investigate the characteristics of energy accumulation and dissipation in sandstone. The results showed that the dissipative energy increased nonlinearly with the increasing axial loading stress. Li et al. [17] investigated the energy evolution characteristics of granite samples under triaxial compression and revealed that the energy evolution could potentially provide an effective reflection of the deformation processes in rock.

The majority of the recent research has been focused on the respective progressive failures and energy evolution of rock. However, few studies have combined the energy evolution with the progressive failure of rocks under compression. Furthermore, the effects of the rock size on the progressive failure and energy evolution have not been fully examined, and experimental results are currently lacking in that area. In this study, sandstone specimens with different sizes were selected for uniaxial and triaxial compression tests, in order to investigate the progressive failures and energy evolution characteristics during loading processes. The goal was to determine the relationship between the energy and characteristic stresses, which may play a significant role in the analyses of pillar failures which occur during underground coal and metal mining processes.

\section{Laboratory Testing}

2.1. Preparation of the Sandstone Specimens. The rock which was used in the present study was sandstone, a rock with a mineral grain size varying from 0.4 to $0.5 \mathrm{~mm}$. The sandstone was sedimentary rock, with a sandy beige appearance on the surface. The main mineral was determined to be quartz, and the sample also contained a small amount of orthoclase. The dry density of the sandstone was approximately $2.373 \mathrm{~g} / \mathrm{cm}^{3}$. In order to ensure that the sandstone specimens had a similar physical state, the $P$-wave of the specimens was measured to single out the specimens with velocities which were too small or large. The $P$-wave velocity ranged from $2238 \mathrm{~m} / \mathrm{s}$ to $2306 \mathrm{~m} / \mathrm{s}$ and showed minimum discreteness in the specimens. Cylindrical specimens measuring $50 \mathrm{~mm}$ in diameter, and 60,100 , and $120 \mathrm{~mm}$ in height, were cored from the sandstone blocks. The ends of the specimens were made flat after being finely cut and polished. Then the prepared specimens were classified into two groups. The sandstone specimens in Group one (including the various heights) were tested using uniaxial compression. The specimens in Group two (including one height and various confining pressures) were used to conduct triaxial compression tests.

2.2. Experimental Setup. In this study, the mechanical properties of sandstone with differential $H / D$ were tested on a stiff servo-controlled testing machine RMT-150B, which had been manufactured by Institute of Rock and Soil Mechanics at the Chinese Academy of Sciences. The test machine was equipped with an axial load capacity of $1,000 \mathrm{kN}$, and a $50 \mathrm{MPa}$ triaxial confining pressure cell [18]. Linear variable differential transformers (LVDTs) were installed for the testing of the axial and circumferential displacements. The specimens with different $H / D$ s were tested at room temperature (approximately $25^{\circ} \mathrm{C}$ ) under a uniaxial compression with a loading rate of $0.002 \mathrm{~mm} / \mathrm{s}$. For the triaxial compression tests, confining pressures and axial stresses were applied at a rate of $0.5 \mathrm{MPa} / \mathrm{s}$ until the designed value was achieved. Then, the loading was switched to an axial displacement control, and the loading rate was set as $0.002 \mathrm{~mm} / \mathrm{s}$, which is the same as the loading rate in uniaxial compression tests.

\section{Experimental Results}

3.1. Stress-Strain Curves of the Sandstone Specimens. Figure 1 provides the stress-strain curves of the sandstone samples with different $H / D$ s under uniaxial compression conditions. The mechanical parameters are listed in Table 1. In Table $1, \varepsilon_{1 \mathrm{p}}$ represents the corresponding axial strain at the peak strength. In this study, Young's modulus $E$ is defined as the slope of the linear elastic phase; $\sigma_{3}$ represents the confining pressure; and $\sigma_{\mathrm{p}}$ is the peak strength of sandstone specimens under the triaxial compression.

In this study's tests, the crack closure, elastic, and small crack growth phases in the stress-strain curves of the sandstone specimens under the uniaxial compression were 


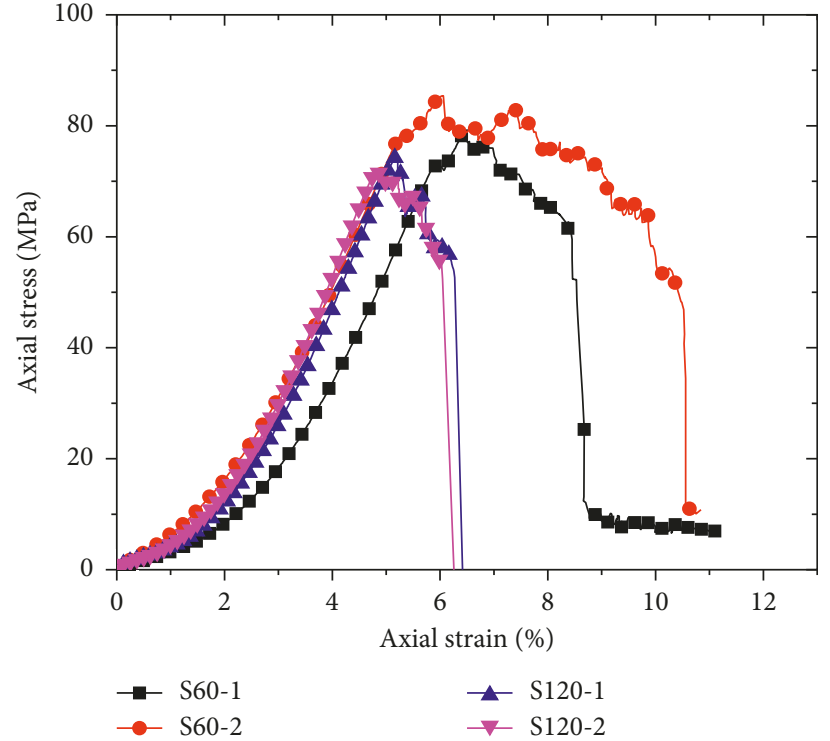

(a)

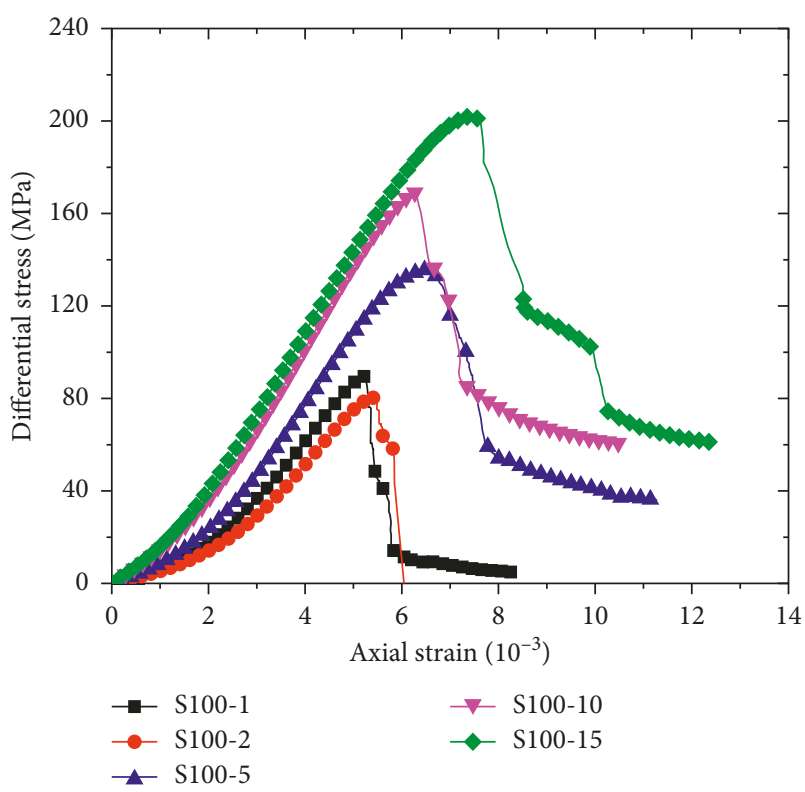

(b)

FIgURE 1: Stress-strain curves of the sandstone specimens with (a) different $H / D$ s and (b) confining pressures.

Table 1: Size, $H / D$, Young's modulus $(E)$, peak strength $\left(\sigma_{\mathrm{p}}\right)$, and peak axial strain $\left(\varepsilon_{1 \mathrm{p}}\right)$ of the sandstone specimens.

\begin{tabular}{|c|c|c|c|c|c|c|c|}
\hline Specimen & Diameter $(\mathrm{mm})$ & Height (mm) & $H / D$ & $\sigma_{3}(\mathrm{MPa})$ & $E(\mathrm{GPa})$ & $\varepsilon_{1 \mathrm{p}}\left(10^{-3}\right)$ & $\sigma_{\mathrm{p}}(\mathrm{MPa})$ \\
\hline S60-1 & 49.68 & 60.75 & 1.2 & 0 & 21.36 & 6.46 & 79.27 \\
\hline S60-2 & 49.42 & 60.69 & 1.2 & 0 & 22.41 & 6.06 & 85.41 \\
\hline S100-1 & 49.52 & 101.28 & 2 & 0 & 26.11 & 5.21 & 89.50 \\
\hline S100-2 & 49.56 & 99.62 & 2 & 0 & 24.14 & 5.43 & 80.28 \\
\hline S100-3 & 49.73 & 100.01 & 2 & 5 & 31.08 & 7.38 & 135.5 \\
\hline S100-4 & 49.49 & 101.30 & 2 & 10 & 35.72 & 7.91 & 169.2 \\
\hline S100-5 & 49.61 & 100.69 & 2 & 15 & 35.34 & 10.18 & 211.9 \\
\hline S120-1 & 49.45 & 121.3 & 2.4 & 0 & 24.54 & 5.20 & 74.65 \\
\hline S120-2 & 49.55 & 119.9 & 2.4 & 0 & 24.67 & 4.89 & 71.75 \\
\hline
\end{tabular}

examined. However, it should be noted that there was an apparent change observed in postpeak behaviors with the increasing of the confining pressure. Also, brittle failures were observed in the stress-strain curves under the uniaxial compression. It was found that, with the increasing of the confining pressures, strain-softening behaviors were evident, as presented in Figure 1(b).

\subsection{Effect of $H / D$ s and Confining Pressures on Mechanical} Parameters of Sandstone. Figure 2 shows the plots of Young's modulus $(E)$, UCS, and corresponding axial strain at the peak $\left(\varepsilon_{1 \mathrm{p}}\right)$, against the $H / D$ and Young's modulus, with the confining pressure. It can be observed from Figures 2(a) and 2(b) that Young's modulus increased the $H / D$ and the UCS and peak axial strain decreased with the $H / D$. With the increases in confining pressures, Young's modulus was observed to increase, while the increase rate was found to gradually decrease.

Figure 3 presents the variations of the peak strengths and theoretical values which were calculated using the MohrCoulomb (M-C) and Hoek-Brown (H-B) criteria. It can be seen in Figure 3 that the peak strength of the sandstone displayed a distinctly nonlinear increasing behavior with the increasing $\sigma_{3}$. It was found that the majority of test data in this study had deviated from the theoretical results calculated using the $\mathrm{M}-\mathrm{C}$ criterion. However, the theoretical data calculated with the H-B criterion were found to fit more effectively with this study's test data.

\section{Progressive Failure of the Sandstone with Different $H / D$ s and Confining Pressures}

4.1. Characteristics of the Crack Evolution of Sandstone. The failures which occur in rock are the results of the crack evolution, including the crack initiation, propagation, and coalescence. These tensile or shear cracks tend to affect the mechanical properties of the rock or rock mass and thereby have significant influences on the safety of rock engineering. The crack strain of the principal strains was calculated in this study by removing the calculated elastic strains as follows:

$$
\varepsilon_{1}^{\mathfrak{c}}=\varepsilon_{1}-\frac{\sigma_{1}}{E}
$$




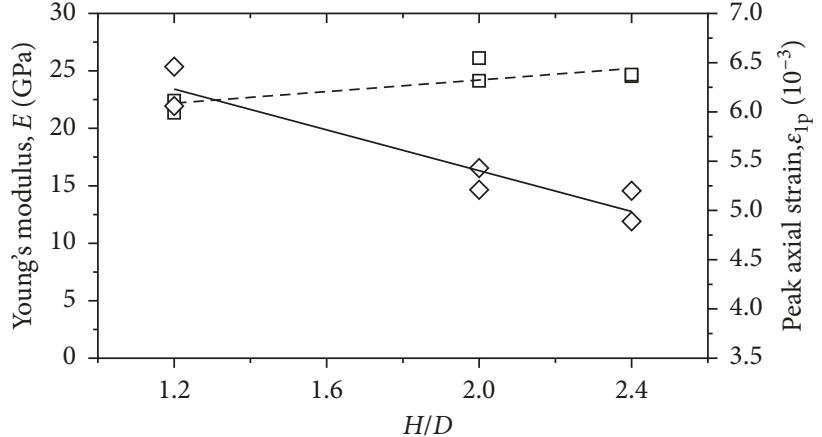

$\square$ Young's modulus

$\diamond$ Peak axial strain

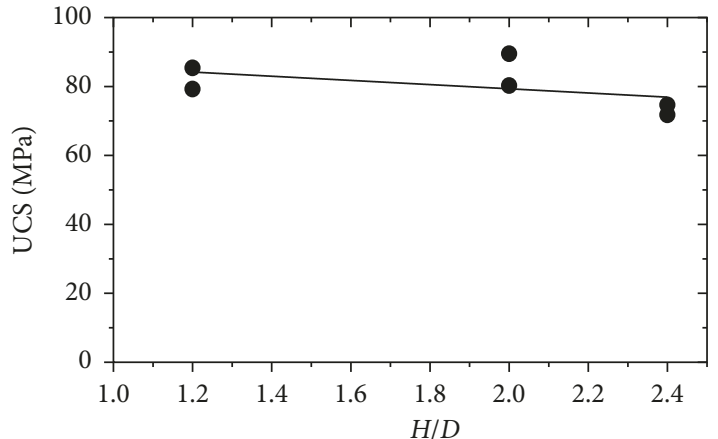

(b)

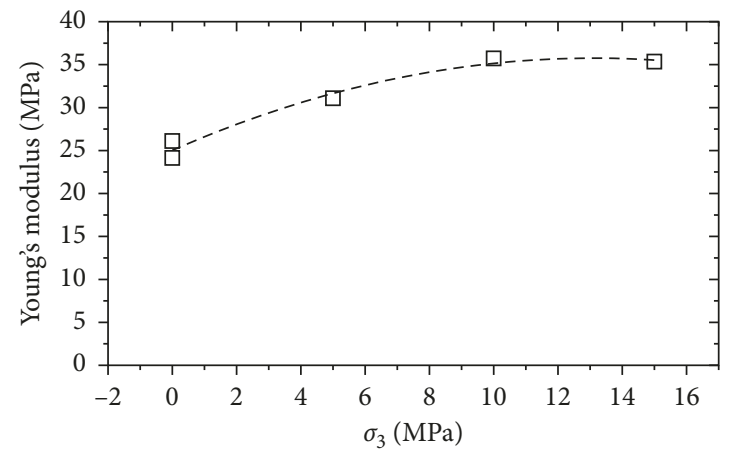

(c)

FIGURE 2: (a) Relationship between Young's modulus and peak axial strain and the $H / D$; (b) relationship between the UCS and the $H / D$; (c) relationship between Young's modulus and the confining pressures.

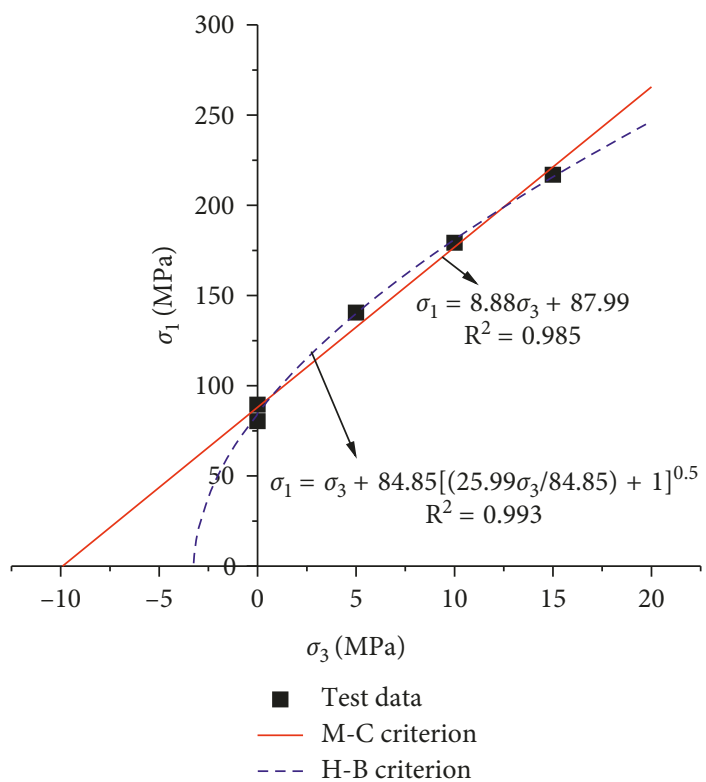

FiguRe 3: Peak strength analysis of the sandstone samples undergoing uniaxial and triaxial compression. The scatter points are test results; the red line represents the theoretical values in accordance with the $\mathrm{M}-\mathrm{C}$ criterion; and the blue line represents the theoretical values calculated by the H-B criterion. 
where $\varepsilon_{1}^{\mathrm{c}}$ is the crack axial strain; $\varepsilon_{1}$ is the axial strain; and $\sigma_{1}$ and $\sigma_{3}$ represent the axial stress and confining pressure, respectively.

Under the condition of triaxial compression, the axial principal stress was the differential stress $\sigma_{1}-\sigma_{3}$. Therefore, the crack axial strain of the sandstone specimens under the triaxial compression could be calculated by

$$
\varepsilon_{1}^{c}=\varepsilon_{1}-\frac{\sigma_{1}-\sigma_{3}}{E} .
$$

Then, in accordance with Equations (1) and (2), the crack strain of the sandstone could be calculated. Figure 4 provides the relationship between the crack axial strain and the axial stress. As can be seen in Figure 4, four phases could be determined based on the crack axial strain. The first phase was a crack closure phase, in which the axial stress displayed a nonlinear increase trend due to the closure of the cracks. Then, the second phase was an elastic phase, in which the crack axial strain remained as a constant, and the axial stress increased vertically. The interval point between the crack closure and elastic phases was $\left(\varepsilon_{1}^{\mathcal{c c}}\right.$, $\left.\sigma_{\mathrm{cc}}\right)$, where $\sigma_{\mathrm{cc}}$ represents the crack closure stress and $\varepsilon_{1}^{\mathrm{cc}}$ is the maximum crack axial strain. It was observed that, with the continuing increases in the differential stresses, the cracks began to become initiated and propagated. This phase was referred to as the crack propagation phase. The interval point between the elastic phase and crack propagation phase was $\left(\varepsilon_{1}^{\mathrm{cc}}, \sigma_{\mathrm{cd}}\right)$, where $\sigma_{\mathrm{cd}}$ represents the crack damage stress. Then, after reaching the peak strength, the rock specimen experienced failure, and this phase was referred to as the postpeak phase, where $\varepsilon_{1}^{\mathrm{cp}}$ represents the peak crack axial strain.

Table 2 lists the crack parameters of the sandstone samples which were obtained from Figure 4 and Equations (1) and (2). In this study, in order to analyze the crack closures and damages in detail, the crack closure stress level $\left(\sigma_{\text {cc }} / \sigma_{\mathrm{p}}\right)$, crack damage stress level $\left(\sigma_{\mathrm{cd}} / \sigma_{\mathrm{p}}\right)$, and crack closure strain level $\left(\varepsilon_{1}^{\mathrm{cc}} / \varepsilon_{1}^{\mathrm{cp}}\right)$ were calculated. In the table, $\Delta \varepsilon_{1}^{\mathrm{c}}$ represents the crack propagation strain before the peak strength, which was the difference between $\varepsilon_{1}^{\mathrm{cp}}$ and $\varepsilon_{1}^{\mathrm{cc}}$. As can be seen in Figures 4(a) and 4(b), the crack strain was observed to only minimally change from point A to point $B$. Therefore, the crack closure strain was found to be equal to crack damage strain in this study, and $\Delta \varepsilon_{1}^{c}$ is regarded as the crack propagation strain.

4.2. Crack Closure Stress and Crack Damage Stress. Figure 5 illustrates the relationship between the crack stress and its stress level, and the $H / D$. From Figure 5(a), it can be seen that, with the increases in the $H / D$, the crack closure stresses of the sandstone increased, while the crack damage stresses displayed a decreasing trend. It was known that there were more cracks in the sandstone specimens with larger $H / D$, while the sandstone specimens with smaller $H / D$ possessed fewer cracks. In the specimens with larger $H / D$, the cracks were more difficult to close. Also, damages in the sandstone specimens more easily occurred when more cracks were evident. Therefore, it was concluded that the crack closure stresses increased, and crack damage stresses decreased with the $H / D$.

Figure 5(b) details the observations that the crack closure stress levels increased with the $H / D$. The crack closure stress levels ranged from 0.357 to 0.550 . The crack damage stress levels displayed a slightly increasing trend, and the minimum value was 0.865 . The crack damage stress levels indicated the brittle properties of the sandstone specimens in this study. It was found that the higher the crack damage stress levels were, the more brittle the rock specimens would be.

Figure 6 shows the variations in the crack closure and crack damage stresses, and their stress levels against the confining pressure. From Figure 6(a), it can be seen that, with the increasing of the confining pressures, both the crack closures and crack damage stresses increased. It was observed that, from $\sigma_{3}=0$ to $\sigma_{3}=15 \mathrm{MPa}$, the crack closure stresses of the sandstone specimens increased from 34.19 $\mathrm{MPa}$ to $61.76 \mathrm{MPa}$. The crack damage stresses increased with the confining pressures, due to the confining pressure having a restriction effect on the crack growth. In this study, a linear Mohr-Coulomb criterion and a nonlinear Hoek-Brown criterion were adopted for the purpose of fitting the relationship between the crack closure stresses and crack damage stresses, which can be seen in Figure 6(a). The crack closure stresses displayed a linear behavior with the increasing of the confining pressure. Meanwhile, crack damage stresses displayed a nonlinear increasing behavior, which indicated that the Hoek-Brown criterion had reflected the crack damage stress more effectively than the linear Mohr-Coulomb criterion.

It can be seen in Figure 6(b) that the crack closure stress levels and the crack damage stress levels decreased with the confining pressure. The crack closure stress levels were determined to decrease from 0.451 to 0.306 , and the crack damage stress levels decreased from 0.900 to 0.747 . The decrease in the crack damage stress levels indicated that, with the increasing of the confining pressures, the brittle properties of the sandstone specimens had decreased.

\subsection{Crack Closure Strain and Peak Crack Axial Strain.} Figure 7 details the plots of $\varepsilon_{1}^{\mathrm{cc}}, \varepsilon_{1}^{\mathrm{cp}}, \Delta \varepsilon_{1}^{\mathrm{c}}$, and $\varepsilon_{1}^{\mathrm{cc}} / \varepsilon_{1}^{\mathrm{cp}}$ of the sandstone specimens against the $H / D$. It can be seen from Figure 7 (a) that, with the increasing of the $H / D$ from 1.2 to 2, both $\varepsilon_{1}^{\mathrm{cc}}$ and $\varepsilon_{1}^{\mathrm{cp}}$ decreased and then displayed a slight increase until the $H / D$ reached 2.4. As detailed in Figure $7(\mathrm{~b})$, the crack propagation strain $\Delta \varepsilon_{1}^{c}$ decreased with the increasing $H / D$, which indicated that the smaller crack growth led to failures in the sandstone specimens with larger $H / D$. It was found that the crack closure strain levels increased with the $H / D$, as detailed in Figure $7(\mathrm{c})$. Figures $7(\mathrm{~b})$ and $7(\mathrm{c})$ illustrate that the sandstone specimens with larger $H / D$ produced less crack strain before the peak strength and also were more brittle than the sandstone specimens with smaller H/D.

The relationship between the crack strain (levels) and the confining pressures are presented in Figure 8. From 


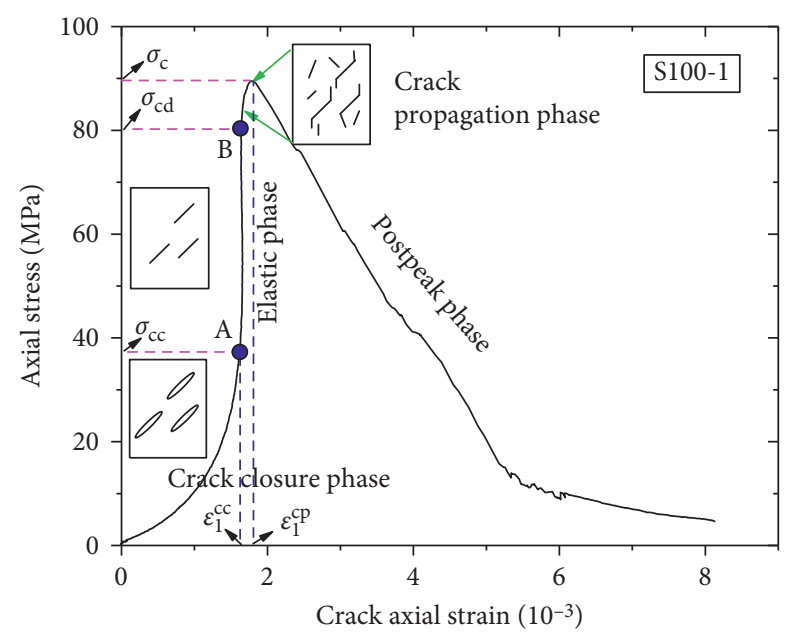

(a)

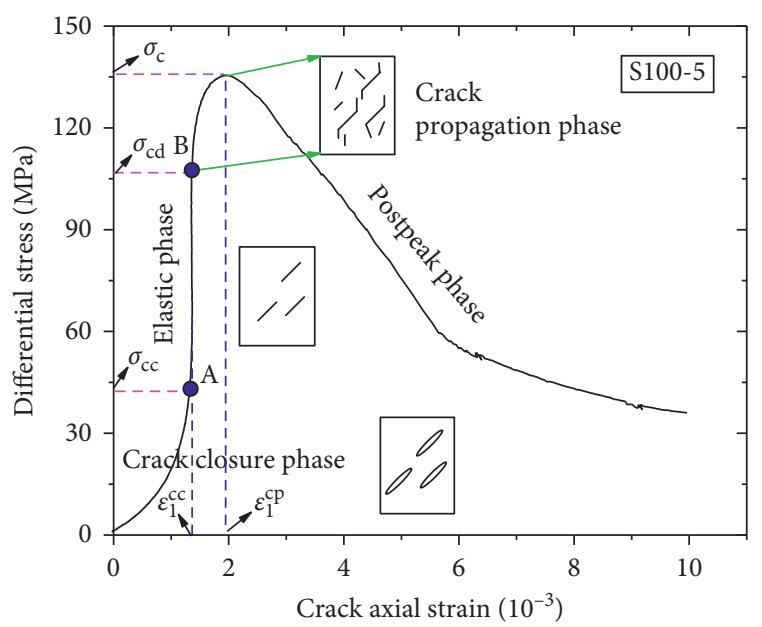

(b)

FIGURE 4: The relationship between the crack axial strain and the axial stress: (a) data from the sandstone specimen S100-1; (b) data from the sandstone specimen S100-3.

TABLE 2: Crack parameters of the sandstone specimens.

\begin{tabular}{|c|c|c|c|c|c|c|c|c|}
\hline Sample & $\varepsilon_{1}^{\mathrm{cc}}\left(10^{-3}\right)$ & $\sigma_{\mathrm{cc}}(\mathrm{MPa})$ & $\sigma_{\mathrm{cd}}(\mathrm{MPa})$ & $\varepsilon_{1}^{\mathrm{cp}}\left(10^{-3}\right)$ & $\Delta \varepsilon_{1}^{\mathcal{c}}\left(10^{-3}\right)$ & $\varepsilon_{1}^{\mathrm{cc}} / \varepsilon_{1}^{\mathrm{cp}}$ & $\sigma_{\mathrm{cc}} / \sigma_{\mathrm{p}}$ & $\sigma_{\mathrm{cd}} / \sigma_{\mathrm{p}}$ \\
\hline S60-1 & 2.344 & 28.32 & 72.84 & 2.704 & 0.359 & 0.867 & 0.357 & 0.919 \\
\hline S60-2 & 1.645 & 33.63 & 76.75 & 2.229 & 0.584 & 0.738 & 0.394 & 0.898 \\
\hline S100-1 & 1.594 & 34.19 & 80.57 & 1.792 & 0.198 & 0.890 & 0.382 & 0.900 \\
\hline S100-2 & 1.853 & 36.20 & 69.46 & 2.106 & 0.253 & 0.880 & 0.451 & 0.865 \\
\hline S100-3 & 1.323 & 43.14 & 107.5 & 1.949 & 0.626 & 0.679 & 0.318 & 0.793 \\
\hline S100-4 & 1.134 & 60.84 & 130.7 & 1.572 & 0.438 & 0.721 & 0.360 & 0.772 \\
\hline S100-5 & 0.893 & 61.76 & 150.8 & 1.608 & 0.715 & 0.555 & 0.306 & 0.747 \\
\hline S120-1 & 2.053 & 38.96 & 68.56 & 2.163 & 0.110 & 0.949 & 0.522 & 0.919 \\
\hline S120-2 & 1.847 & 39.49 & 69.41 & 1.989 & 0.142 & 0.929 & 0.550 & 0.967 \\
\hline
\end{tabular}

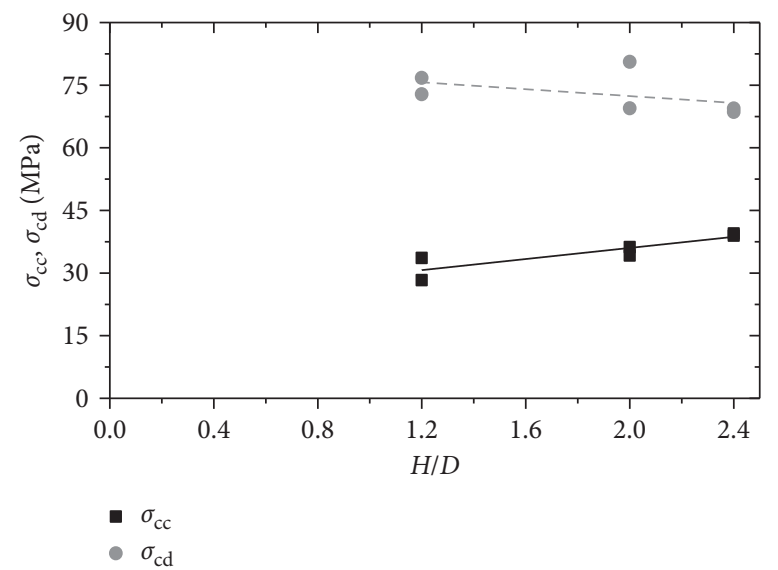

(a)

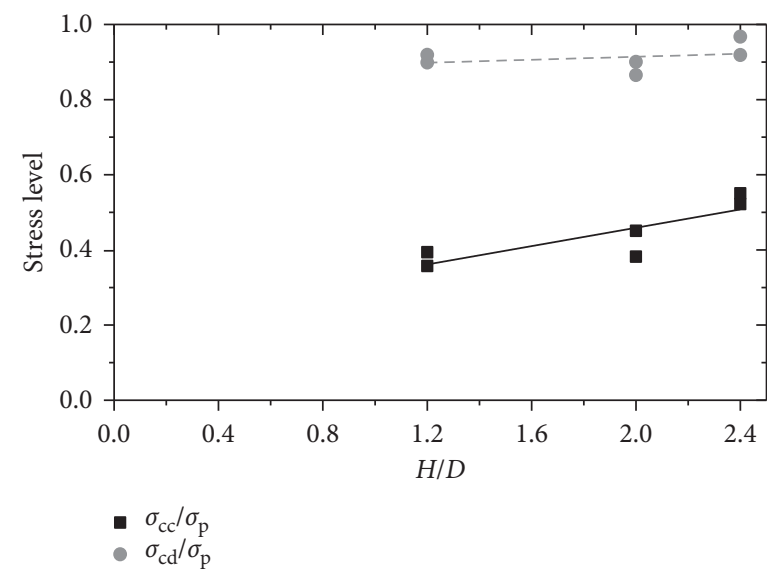

(b)

FIgURE 5: (a) Relationship between the crack closures and damage stresses and the $H / D$; (b) relationship between the stress levels and the $H / D$.

Figure 8(a), it can be seen that the crack closure and peak crack axial strains decreased with the increasing of the confining pressures. During the process of applying the confining pressures, some closure cracks occurred, which led to the crack closure strains of the sandstone specimens decreasing with the confining pressure. Figure 8(b) illustrates the relationship between the crack propagation strain and the confining pressure. It can be seen from Figure $8(\mathrm{~b})$ that crack propagation strain displayed an increasing trend with the confining pressure. 


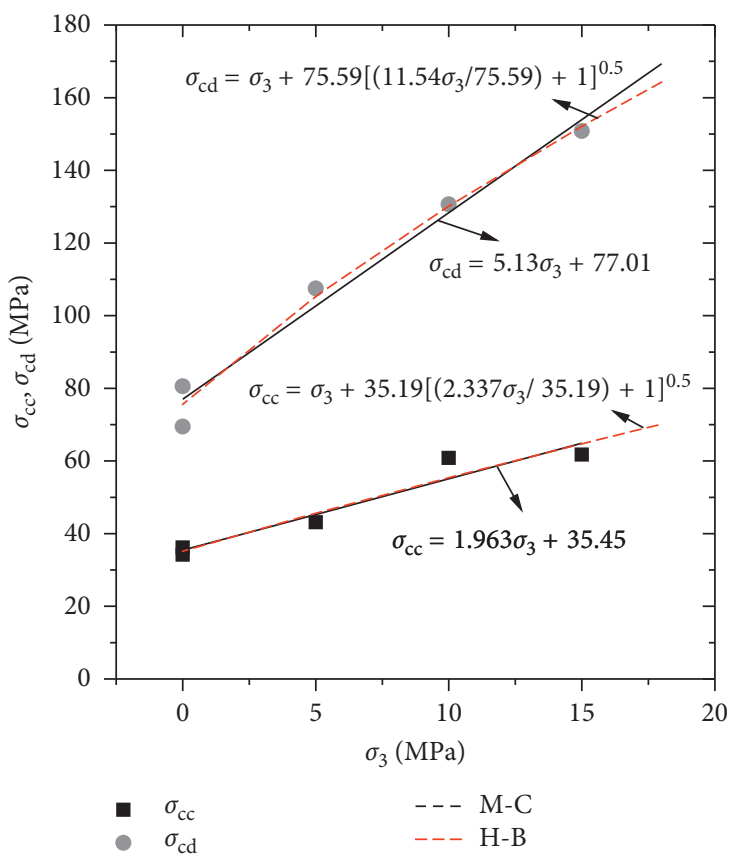

(a)

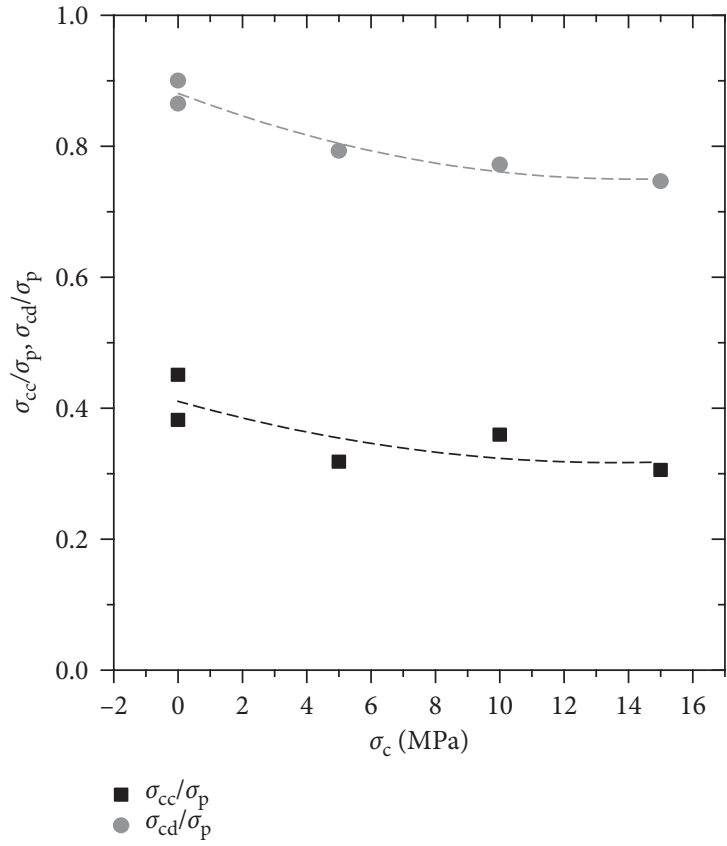

(b)

Figure 6: (a) Variations of the crack closure and crack damage stresses with the confining pressure; (b) relationship between the crack closures, damage stress levels, and confining pressures.
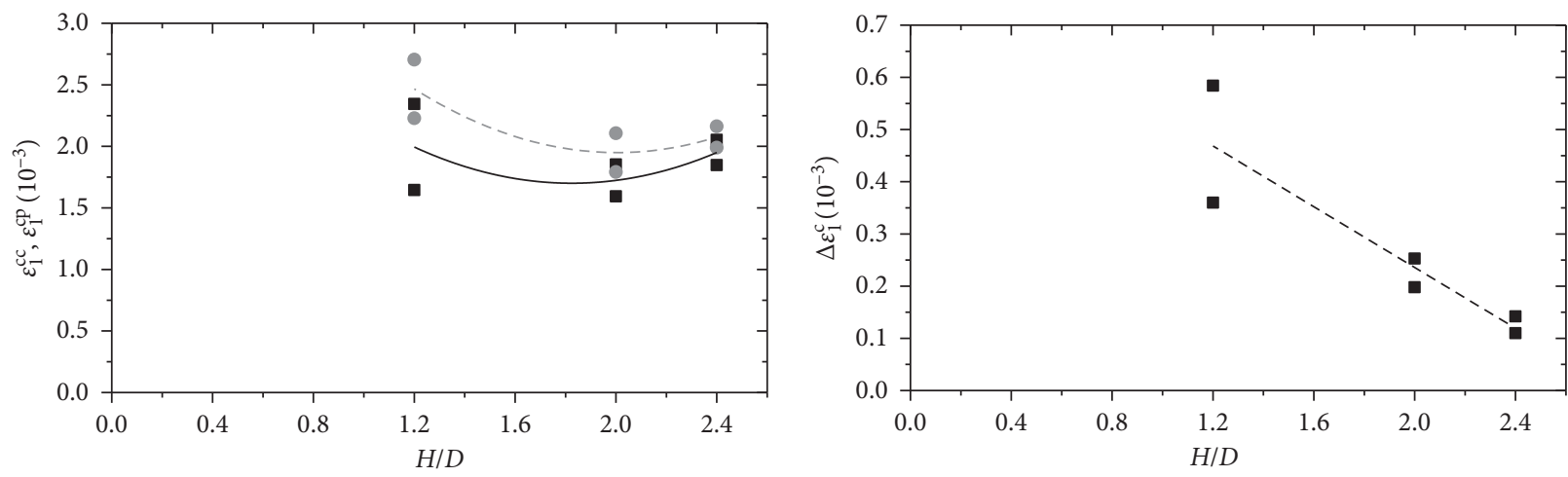

- $\varepsilon_{1}^{\mathrm{cc}}$

(a)

(b)

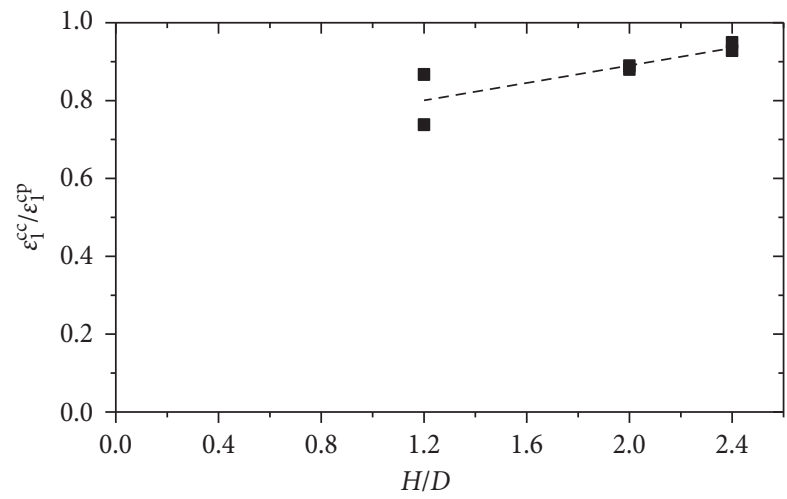

(c)

Figure 7: (a) Relationship between the crack closure and peak crack axial strains and the $H / D$; (b) relationship between the $\Delta \varepsilon_{1}^{\mathrm{c}}$ and the $H / D$; (c) relationship between the $\varepsilon_{1}^{\mathrm{cc}} / \varepsilon_{1}^{\mathrm{cp}}$ and the $H / D$. 

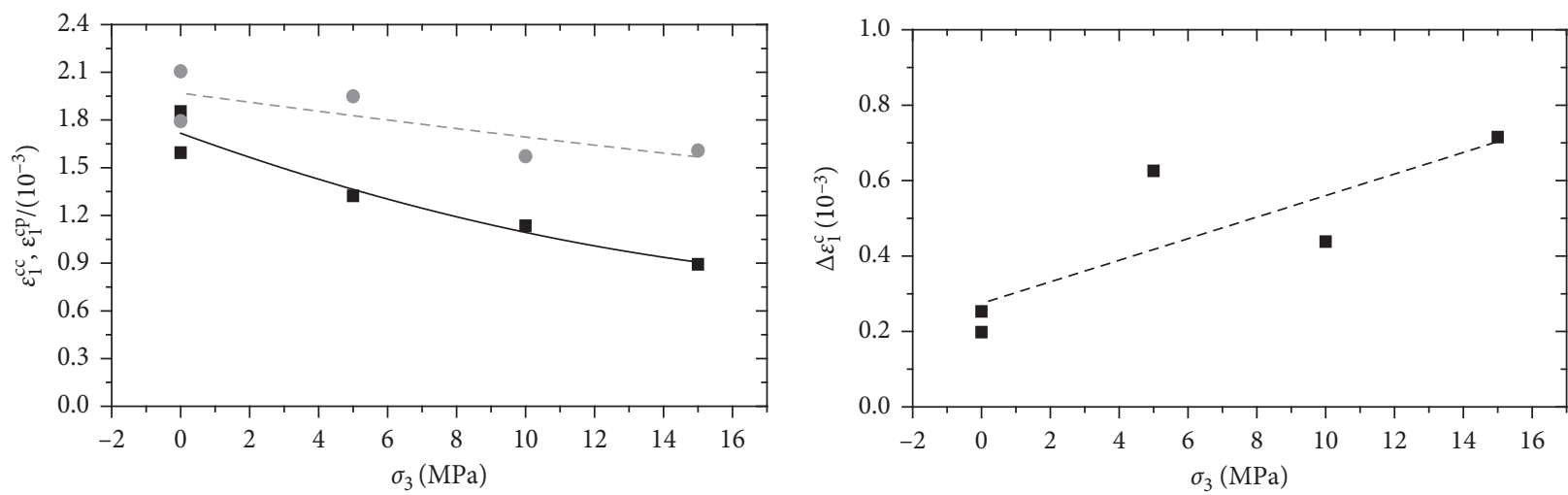

- $\varepsilon_{1}^{\mathrm{cc}}$

- $\varepsilon_{1}^{\mathrm{cp}}$

(a)

(b)

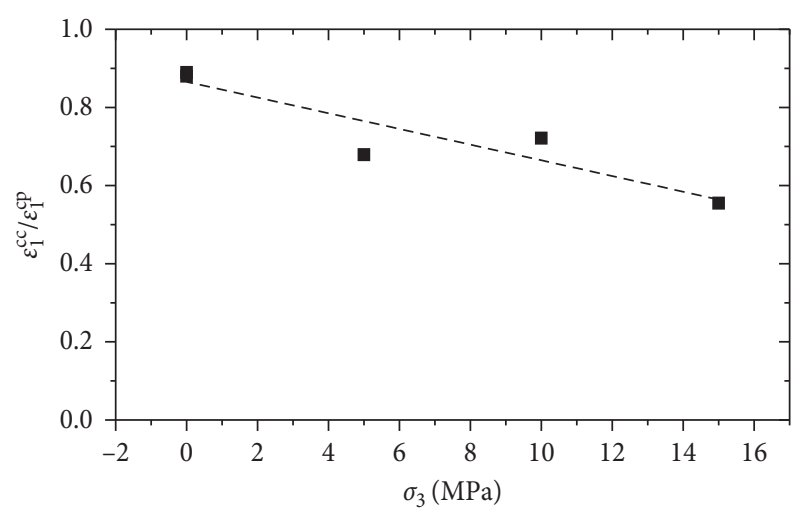

(c)

Figure 8: (a) Relationship between the crack closure and peak crack axial strains and $\sigma_{3}$; (b) relationship between $\Delta \varepsilon_{1}^{c}$ and $\sigma_{3}$; (c) relationship between $\varepsilon_{1}^{\mathrm{cc}} / \varepsilon_{1}^{\mathrm{cp}}$ and $\sigma_{3}$.

Also, Figure 8(c) illustrates that the crack closure strain levels decreased with the confining pressure. Figures $8(\mathrm{~b})$ and $8(\mathrm{c})$ indicate the findings that the sandstone specimens with larger confining pressure were able to bear larger crack propagation.

\section{Energy Evolution Characteristics of the Sandstone}

5.1. Energy Evolution during the Failure Process of the Sandstone. During the loading process, the closures, initiations, and propagation of the cracks consumed energy, which appeared as acoustic emissions, fracture surface energy before peak strength, and the friction among the fracture surfaces after peak strength. The energy evolution of a rock element under compression has often been calculated by the area of stress-strain curves $[16,17,19]$. Therefore, by integrating the stressstrain curves and stress-crack strain curves of the sandstone specimens, the energy evolution characteristics could be obtained. The energy was calculated by the following equations:

$$
\begin{aligned}
& U^{\mathrm{c}}=\int \sigma_{1} d \varepsilon_{1}, \\
& U^{\mathrm{d}}=\int \sigma_{1} d \varepsilon_{1}^{\mathrm{c}}, \\
& U^{\mathrm{e}}=U^{\mathrm{c}}-U^{\mathrm{d}} .
\end{aligned}
$$

where $U^{\mathrm{c}}, U^{\mathrm{d}}$, and $U^{\mathrm{e}}$ represent the input energy density, dissipative energy density, and elastic density, respectively.

Figure 9 shows the energy evolution characteristics of the sandstone specimens with different $H / D$ s. As can be seen in Figure 9, the crack closure and crack damage stresses, along with the different phases of the stress-strain curves, could be determined based on the evolution of the dissipative energy. During the initial loading process, the input energy was mainly used to close the cracks. Therefore, the dissipative energy was larger than the elastic energy. However, when the elastic energy was larger than the dissipative energy, the one characteristic stress $\sigma_{\mathrm{cc}}^{\prime}$ was determined, which was reflected when the elastic energy began to become larger than the dissipative energy. Then the increase rate of the elastic energy increased, while the increase rate of dissipative energy decreased until reaching zero. It was observed that the 


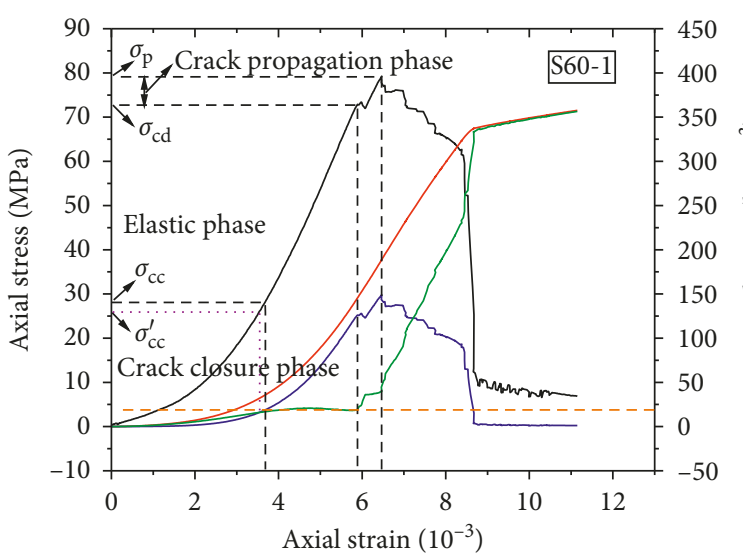

$$
-\begin{array}{ll}
\sigma_{1}-\varepsilon_{1} & -U^{\mathrm{e}}-\varepsilon_{1} \\
U^{\mathrm{c}}-\varepsilon_{1} & -U^{\mathrm{d}}-\varepsilon_{1}
\end{array}
$$

(a)

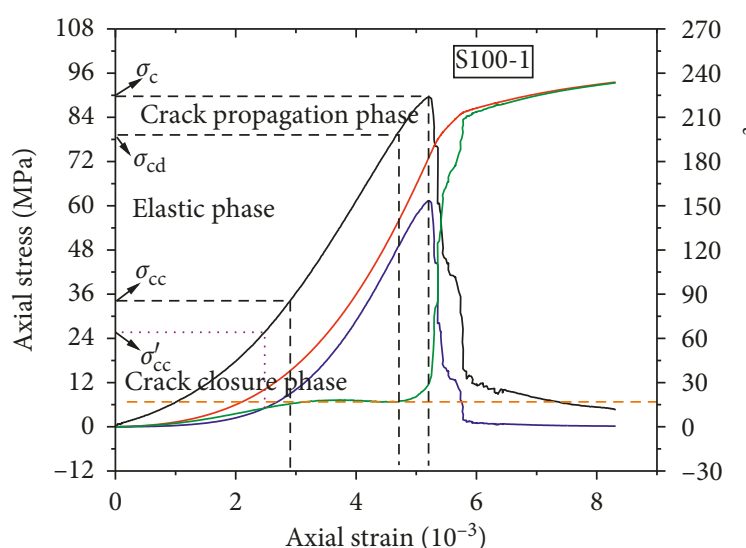

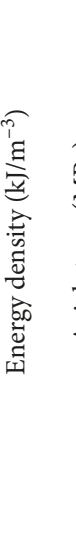

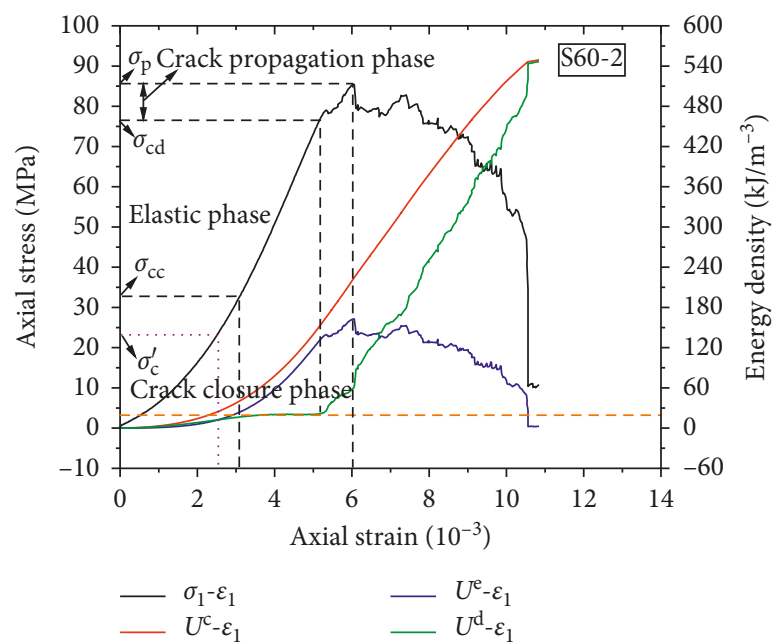

(b)

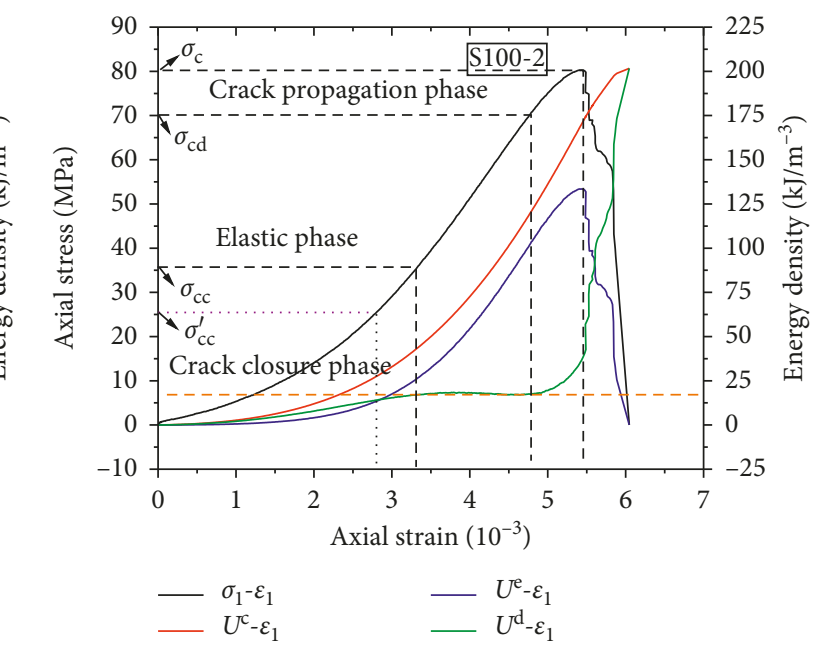

(d)
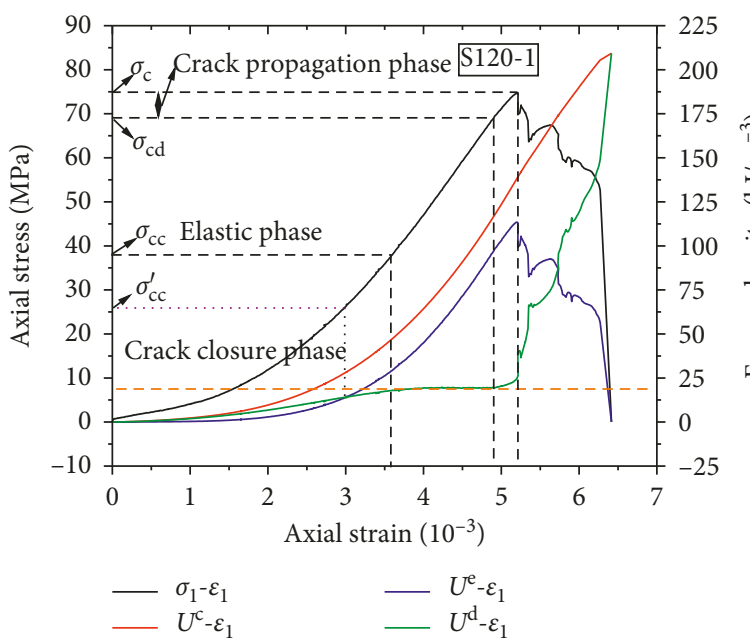

(e)

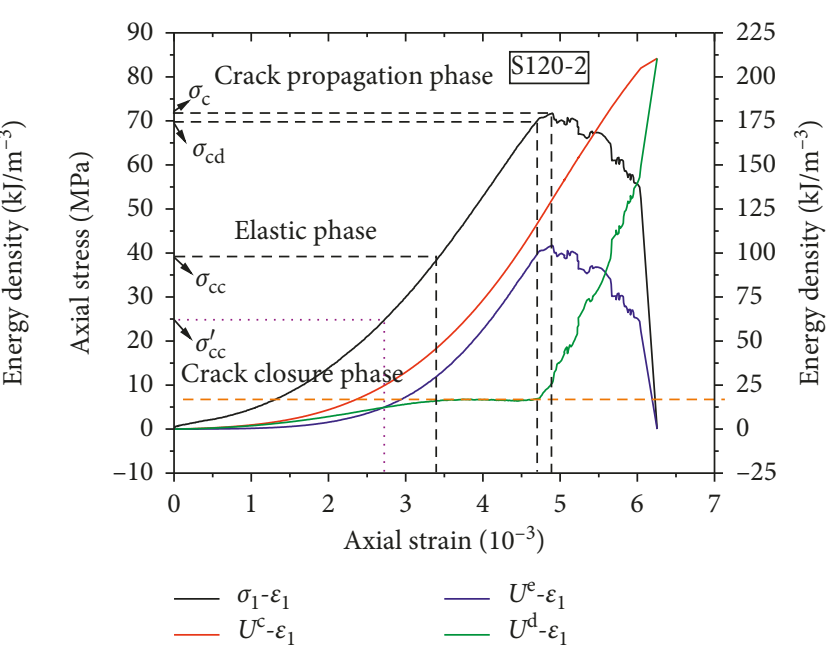

(f)

Figure 9: Energy evolution characteristics of the sandstone specimens with different $H / D$ s. 


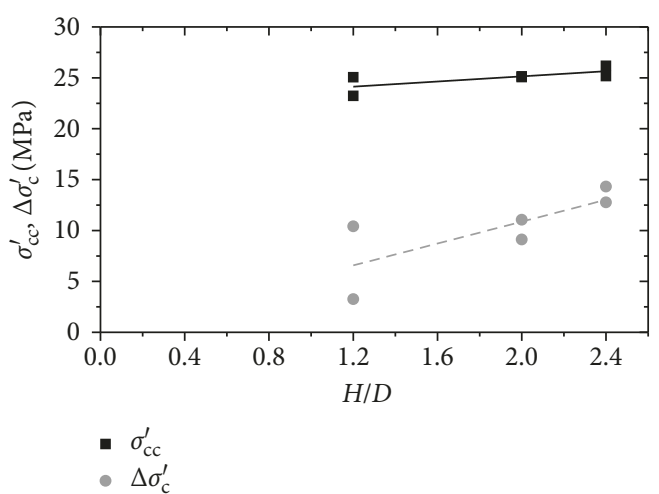

(a)

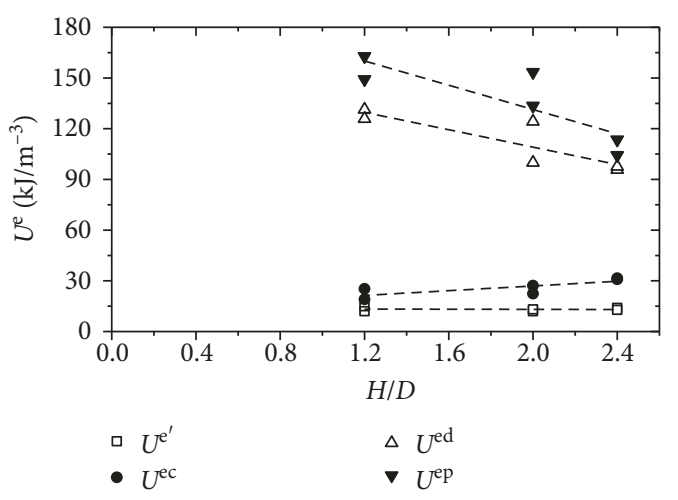

(c)

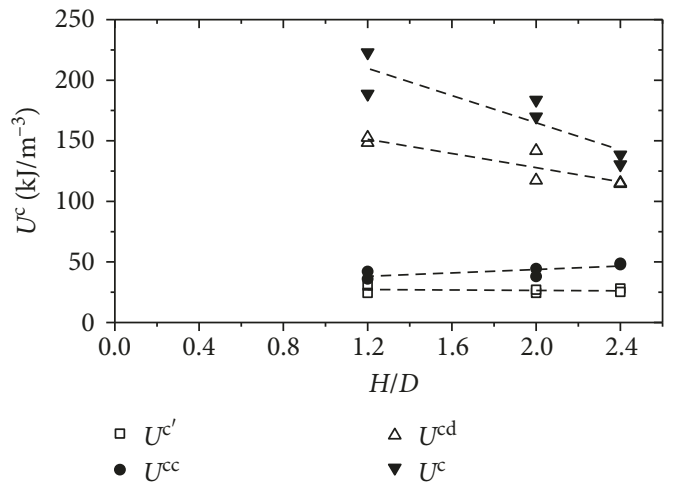

(b)

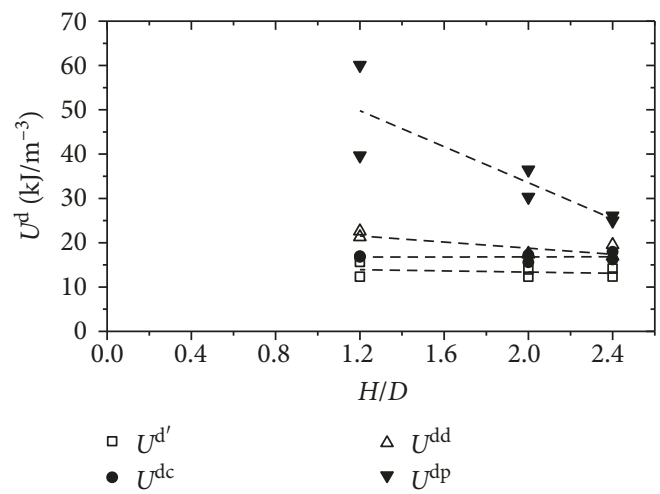

(d)

FIGURE 10: (a) Relationship among $\sigma_{\mathrm{cc}}^{\prime}, \Delta \sigma_{\mathrm{c}}^{\prime}$, and $\mathrm{H} / \mathrm{D}$; (b) relationship between input energy density and $H / D$; (c) relationship between elastic energy density and $H / D$; (d) relationship between dissipative energy density and $H / D$.

value of the dissipative energy had primarily remained as a constant. It was determined that the dissipative energy underwent only minor changes, due to the fact that the specimen was in the elastic phase, and the cracks were closed. At that time, we can get the crack closure stresses. However, when the dissipative energy started increasing, the crack damage stresses, along with the crack propagation phase before peak strength, could be obtained. As previously mentioned, $U^{\mathrm{c}}, U^{\mathrm{d}}$, and $U^{\mathrm{e}}$ represent the input energy density, dissipative energy density, and elastic density, respectively. The superscripts ', c d, $\mathrm{p}$ were added to identify the energy densities at the different phases. For example, $U^{\text {c, }}$ denotes the corresponding input energy density when the axial stress was $\sigma_{c c}^{\prime} ; U^{\text {ec }}$ represents the corresponding elastic energy at the axial stress of $\sigma_{c c} ; U^{\text {dd }}$ is defined as the dissipative energy density when the specimens experienced damages at the axial stress of $\sigma_{\mathrm{cd}}$; and $U^{\mathrm{dp}}$ is the corresponding dissipative energy density at the peak strength $\sigma_{\mathrm{p}}$.

\subsection{Relationship between Energy Evolution at Different} Failure Phases. Figure 10 shows the plots of $\sigma_{\mathrm{cc}}^{\prime}$ and $\Delta \sigma_{\mathrm{c}}^{\prime}$, and the energy densities during the different phases against the H/D. $\Delta \sigma_{\mathrm{c}}^{\prime}$ was defined as the difference between $\sigma_{\mathrm{cc}}^{\prime}$ and $\sigma_{\mathrm{cc}}$. If $\Delta \sigma_{\mathrm{c}}^{\prime}$ becomes smaller, then the cracks become approximately closed, and the majority of the input energy transforms into dissipative energy. As detailed in Figure 10(a), with the increasing of the $H / D$, both $\sigma_{\mathrm{cc}}^{\prime}$ and $\Delta \sigma_{\mathrm{c}}^{\prime}$ increased, which indicated that an increasing amount of the input energy was being transformed into elastic energy during the crack closure phase. Figure 10(c) illustrates that the elastic energy density increased with the $H / D$.

In Figures 10(b)-10(d), it can be seen that the energy densities, including $U^{\mathrm{c}_{1}}, U^{\mathrm{e}^{\prime}}$, and $U^{\mathrm{d}^{\prime}}$, displayed nearly no changes with the increasing of the $H / D$. These findings indicated that during the initial loading process, the majority of the input energy was transformed into dissipative energy and was not related to the $H / D$. The energy densities $\left(U^{\mathrm{cc}}, U^{\mathrm{ec}}\right.$, and $\left.U^{\mathrm{dc}}\right)$ of the crack closure stresses were observed to have slight increases with the $H / D$, which indicated that the specimens with larger $H / D$ required more energy to close the cracks. When the specimens experienced damages, the energy densities $\left(U^{\text {cd }}, U^{\text {ed }}\right.$, and $\left.U^{\text {dd }}\right)$ decreased with the $H / D$, which indicated that damages could occur in the specimens with smaller energy. The energy densities ( $U^{\mathrm{cp}}, U^{\mathrm{ep}}$, and $U^{\mathrm{dp}}$ ) decreased with $H / D$ when failures occurred in the specimens. These findings suggested that smaller energy input could cause failures in rock with larger $H / D$.

Figure 11 shows the relationship between the energy densities and characteristic stresses during the different phases. Overall, the input energy and elastic energy densities during the different phases displayed an increasing trend with increases in the characteristic stresses. The dissipative energy densities at the axial stresses of $\sigma_{\mathrm{cc}}^{\prime}$ and $\sigma_{\mathrm{p}}$ displayed 

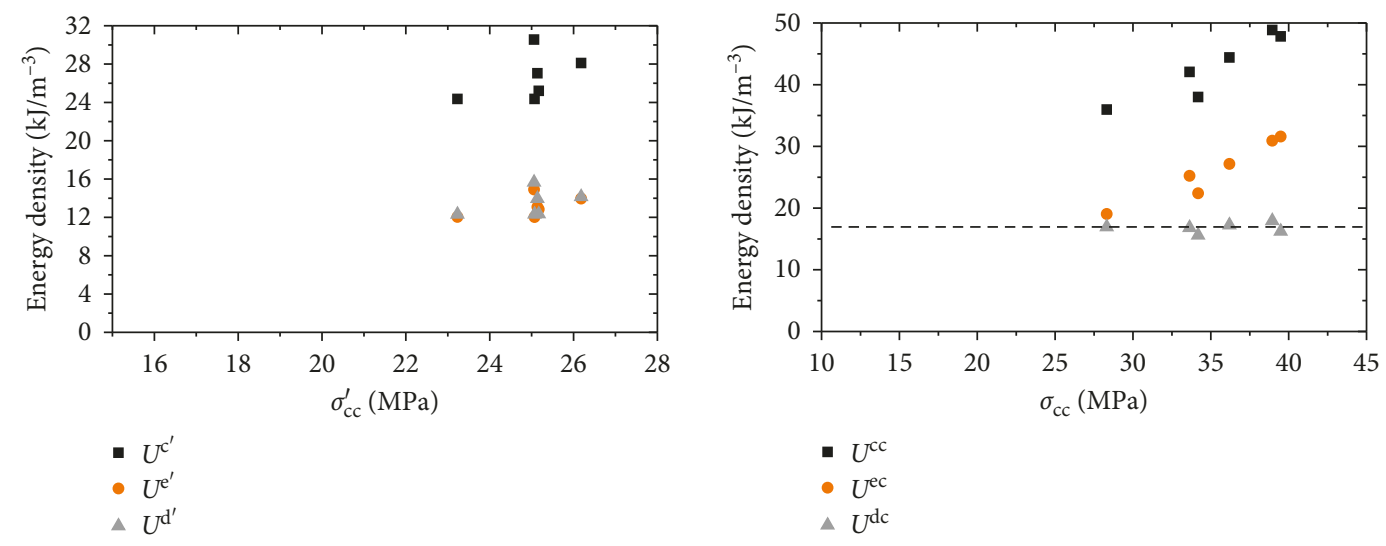

(a)
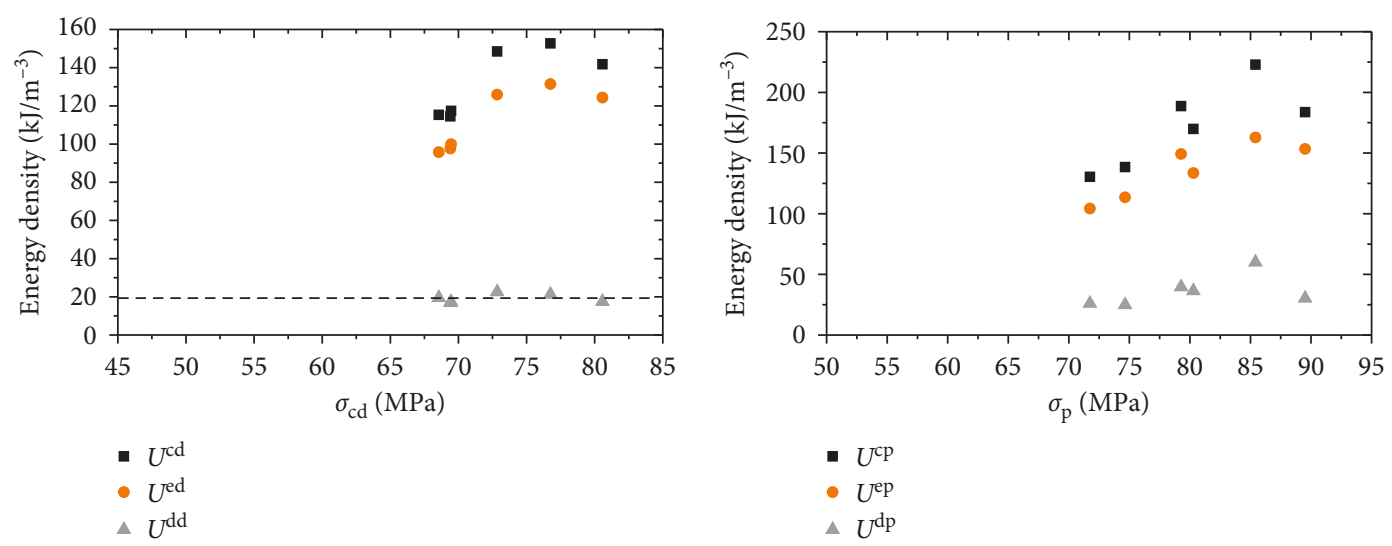

(c)

(d)

FIGURE 11: Relationship between the energy densities and the characteristic stresses during the different phases: (a) $\sigma_{c c}^{\prime}$; (b) $\sigma_{\text {cc }}$; (c) $\sigma_{\text {cd }}$; (d) $\sigma_{\mathrm{p}}$.

slight increase with increase in the characteristic stresses. However, at the axial stresses of $\sigma_{c c}$ and $\sigma_{c d}$, the dissipative energy densities displayed nearly no changes with increasing of $\sigma_{\mathrm{cc}}$ and $\sigma_{\mathrm{cd}}$. For example, the dissipative energy density ranged from $15.60 \mathrm{~kJ} / \mathrm{m}^{-3}$ to $17.94 \mathrm{~kJ} / \mathrm{m}^{-3}$, as shown in Figure 11(b), and the average value was determined to be $16.79 \mathrm{~kJ} / \mathrm{m}^{-3}$, thus revealing little change.

\section{Conclusions}

In this study, the progressive failure and energy evolution characteristics of sandstone specimens with different $H / D s$ were systematically examined by performing a series of uniaxial and triaxial compression tests. Then, based on the experimental results, the following conclusions were drawn:

(1) The results of this experimental study showed that Young's modulus increased with the increases of the $H / D$. However, the peak axial strain and UCS decreased. Young's modulus was found to increase with the confining pressure, while its increase rate gradually decreased. The triaxial compressive strength was observed to increase with the confining pressure, and the Hoek-Brown criterion was determined to be a closer fit for the decreases in the strength characteristics of the sandstone specimens in this study, when compared to the Mohr-Coulomb criterion.

(2) On the basis of the definition of the crack strain levels, the crack evolution characteristics of the sandstone specimens, along with its progressive failure process, were fully discussed. The stress-strain curves were divided into four phases, and the characteristic stresses $\left(\sigma_{\mathrm{cc}}, \sigma_{\mathrm{cd}}\right.$, and $\left.\sigma_{\mathrm{p}}\right)$, as well as their corresponding crack strains $\left(\varepsilon_{1}^{\mathrm{cc}}, \varepsilon_{1}^{\mathrm{cd}}\right.$, and $\left.\varepsilon_{1}^{\mathrm{cp}}\right)$, were obtained through the evolution of the crack axial strain. Both the crack closure stresses and the crack closure stress levels were observed to increase with the $H / D$. Meanwhile, the crack damage stresses decreased, and the stress levels increased, with the $H / D$. It was found that the crack closure and peak crack axial strains decreased with the $H / D$, while their increase rates gradually decreased, and the crack closure strain levels increased. Also, the crack propagation strain levels decreased with the $H / D$, which indicated that the smaller crack growth of rock with larger $H / D$ can result in rock failures.

(3) With increasing of the confining pressures, both the crack closure and crack damage stresses increased, but their stress levels decreased. The crack closure, peak crack axial, and crack closure strain levels 
decreased with the confining pressure. Meanwhile, the crack propagation strain increased with the confining pressure, which indicated that the rock with higher confining pressures was able to withstand higher crack growth than the rock with lower confining pressures.

(4) In this study, based on the evolution characteristics of the dissipative energy, the progressive failure processes of sandstone could also be determined. Other characteristic stresses $\left(\sigma_{\mathrm{cc}}^{\prime}\right.$ and $\left.\Delta \sigma_{\mathrm{c}}^{\prime}\right)$ were obtained at the points where the elastic energy equaled the dissipative energy. With the increasing $H / D, \sigma_{\mathrm{cc}}^{\prime}$ and $\Delta \sigma_{\mathrm{c}}^{\prime}$ were also observed to increase, which indicated that during the crack closure phase, the cracks were difficult to close in the specimens with larger $H / D$. With the increases in the $H / D$, the energy at the axial stresses of $\sigma_{\mathrm{cc}}^{\prime}$ experienced only minor changes, and only slight increases at the axial stresses of $\sigma_{\text {cc }}$ were observed. The energy at the crack damage stresses and peak strength decreased with the $H / D$, which indicated that smaller energy input could result in failures in the rock with larger $H / D$.

(5) With the increases in the characteristic stresses, the input and elastic energy densities were found to increase. The dissipative energy densities displayed on slight increases with the increases of $\sigma_{\mathrm{cc}}^{\prime}$ and $\sigma_{\mathrm{p}}$ while only minor changes were observed with the increase of $\sigma_{\mathrm{cc}}$ and $\sigma_{\mathrm{cd}}$.

\section{Data Availability}

The data used to support the findings of this study are available from the corresponding author upon request.

\section{Conflicts of Interest}

The authors declare that they have no conflicts of interest.

\section{Acknowledgments}

This research was financially supported by the China $\mathrm{Na}$ tional Natural Science Foundation (Grant No. 51109076) and the Key Scientific and Technological Project of Henan Province (Grant No. 152102210316).

\section{References}

[1] Z. T. Bieniawski, "Mechanism of brittle fracture of rock," International Journal of Rock Mechanics and Mining Sciences and Geomechanics Abstracts, vol. 4, no. 4, pp. 395-430, 1967.

[2] C. D. Martin and N. A. Chandler, "The progressive fracture of Lac du Bonnet granite," International Journal of Rock Mechanics and Mining Sciences, vol. 31, no. 6, pp. 643-659, 1994.

[3] E. Eberhardt, D. Stead, B. Stimpson, and R. S. Read, "Changes in acoustic event properties with progressive fracture damage," International Journal of Rock Mechanics and Mining Sciences, vol. 34, no. 3-4, pp. 71.e1-71.e12, 1997.

[4] E. Eberhardt, D. Stead, B. Stimpson, and R. S. Read, "Identifying crack initiation and propagation thresholds in brittle rock," Canadian Geotechnical Journal, vol. 35, no. 2, pp. 222-233, 1998.

[5] M. Cai, P. K. Kaiser, Y. Tasaka, T. Maejima, H. Morioka, and M. Minami, "Generalized crack initiation and crack damage stress thresholds of brittle rock masses near underground excavations," International Journal of Rock Mechanics and Mining Sciences, vol. 41, no. 5, pp. 833-847, 2004.

[6] L. Xue, S. Qin, Q. Sun, Y. Wang, L. M. Lee, and W. Li, “A study on crack damage stress thresholds of different rock types based on uniaxial compression tests," Rock Mechanics and Rock Engineering, vol. 47, no. 4, pp. 1183-1195, 2014.

[7] Z. T. Bieniawski, "The effect of specimen size on compressive strength of coal," International Journal of Rock Mechanics and Mining Sciences and Geomechanics Abstracts, vol. 5, no. 4, pp. 325-335, 1968.

[8] H. R. Pratt, A.D. Black, W.S. Brown, and W.F. Brace, "The effect of speciment size on the mechanical properties of unjointed diorite," International Journal of Rock Mechanics and Mining Sciences and Geomechanics Abstracts, vol. 9, no. 4, pp. 513-516, 1972.

[9] W. F. Brace, "The effect of size on mechanical properties of rock," Geophysical Research Letters, vol. 8, no. 7, pp. 651-652, 1981.

[10] E. Hoek and E. T. Brown, "Practical estimates of rock mass strength," International Journal of Rock Mechanics and Mining Sciences and Geomechanics Abstracts, vol. 34, no. 8, pp. 1165-1186, 1997.

[11] R. Yoshinaka, M. Osada, H. Park, T. Sasaki, and K. Sasaki, "Practical determination of mechanical design parameters of intact rock considering scale effect," Engineering Geology, vol. 96, no. 3-4, pp. 173-186, 2008.

[12] W. J. Darlington, P. G. Ranjith, and S. K. Choi, "The effect of specimen size on strength and other properties in laboratory testing of rock and rock-like cementitious brittle materials," Rock Mechanics and Rock Engineering, vol. 44, no. 5, pp. 513-529, 2011.

[13] H. Masoumi, S. Saydam, and P. C. Hagan, "Unified size-effect law for intact rock," International Journal of Geomechanics, vol. 16, no. 2, article 04015059, 2016.

[14] D. Huang and Y. Li, "Conversion of strain energy in triaxial unloading tests on marble," International Journal of Rock Mechanics and Mining Sciences, vol. 66, pp. 160-168, 2014.

[15] R. Peng, Y. Ju, J. G. Wang, H. Xie, F. Gao, and L. Mao, "Energy dissipation and release during coal failure under conventional triaxial compression," Rock Mechanics and Rock Engineering, vol. 48, no. 2, pp. 509-526, 2015.

[16] Q. Meng, M. Zhang, L. Han, H. Pu, and T. Nie, "Effects of acoustic emission and energy evolution of rock specimens under the uniaxial cyclic loading and unloading compression," Rock Mechanics and Rock Engineering, vol. 49, no. 10, pp. 3873-3886, 2016.

[17] D. Li, Z. Sun, T. Xie, X. Li, and P. G. Ranjith, "Energy evolution characteristics of hard rock during triaxial failure with different loading and unloading paths," Engineering Geology, vol. 228, pp. 270-281, 2017.

[18] Z. Meng and J. Pan, "Correlation between petrographic characteristics and failure duration in clastic rocks," Engineering Geology, vol. 89, no. 3-4, pp. 258-265, 2007.

[19] H. Xie, L. Li, R. Peng, and Y. Ju, "Energy analysis and criteria for structural failure of rocks," Journal of Rock Mechanics and Geotechnical Engineering, vol. 1, no. 1, pp. 11-20, 2009. 


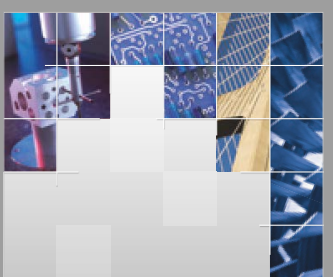

\section{Enfincering}
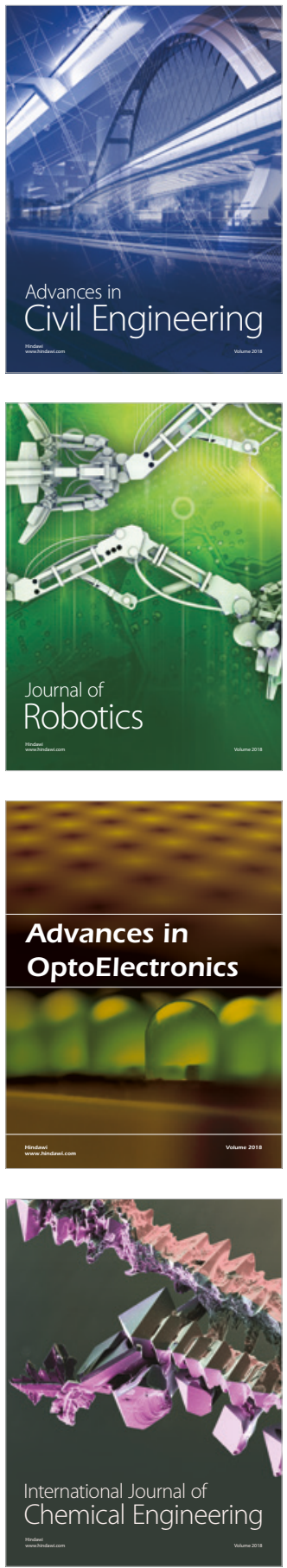

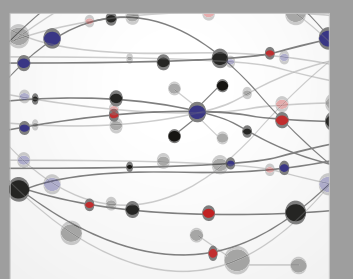

\section{Rotating \\ Machinery}

The Scientific World Journal

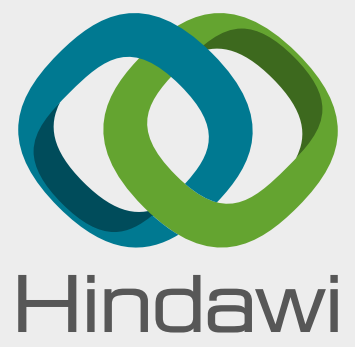

Submit your manuscripts at

www.hindawi.com
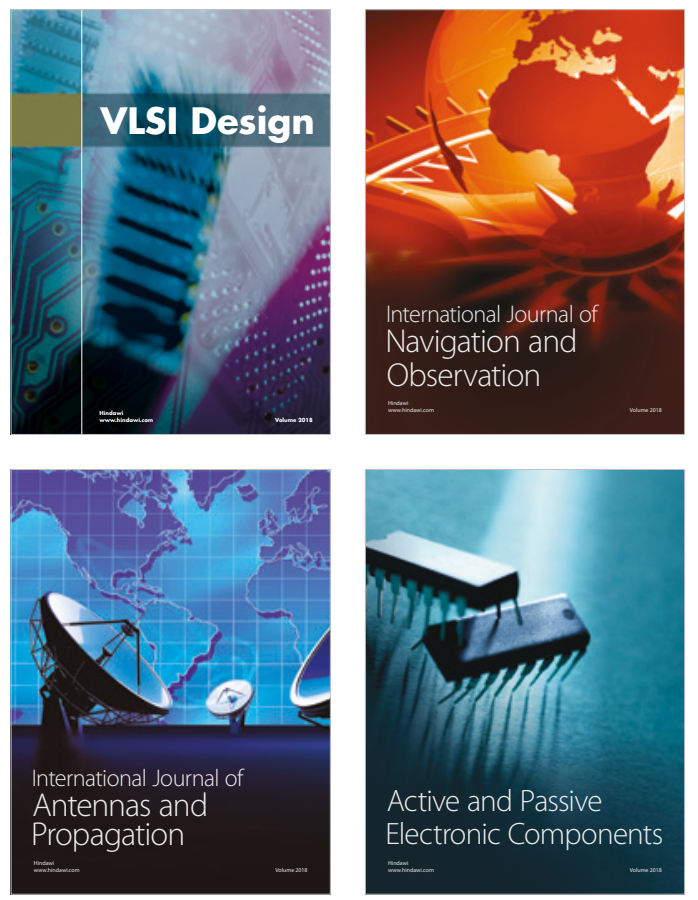
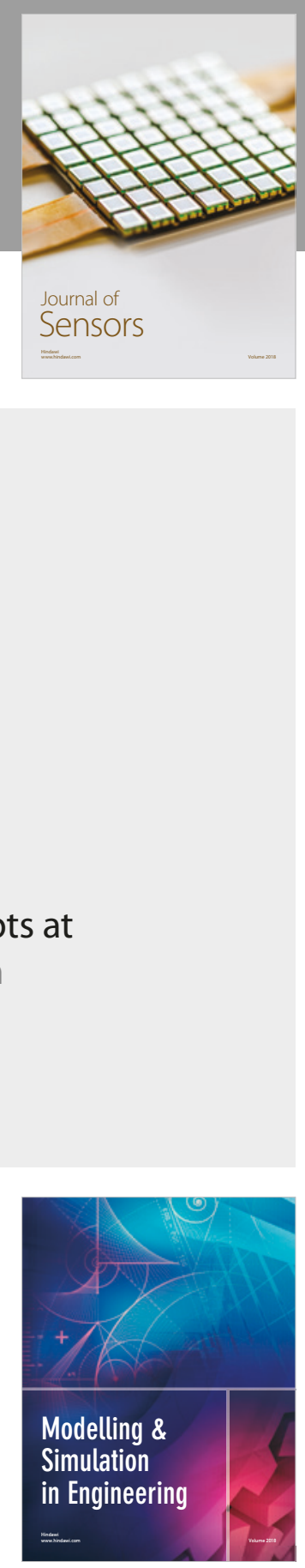

\section{Advances \\ Multimedia}
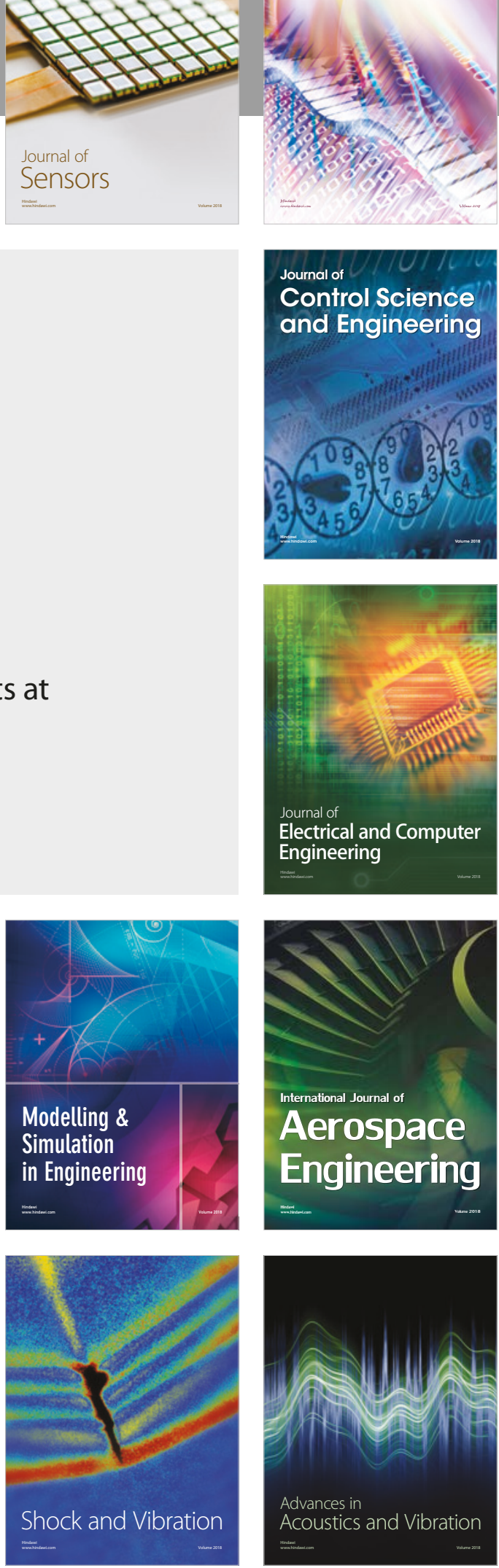